Portland State University

PDXScholar

$5-5-1992$

\title{
A Comparison of Two Kindergarten Screening Instruments in One Population
}

Therese Marie Westrup

Portland State University

Follow this and additional works at: https://pdxscholar.library.pdx.edu/open_access_etds

Part of the Speech and Rhetorical Studies Commons

Let us know how access to this document benefits you.

\section{Recommended Citation}

Westrup, Therese Marie, "A Comparison of Two Kindergarten Screening Instruments in One Population" (1992). Dissertations and Theses. Paper 4525.

https://doi.org/10.15760/etd.6409

This Thesis is brought to you for free and open access. It has been accepted for inclusion in Dissertations and Theses by an authorized administrator of PDXScholar. Please contact us if we can make this document more accessible: pdxscholar@pdx.edu. 
AN ABSTRACT OF THE THESIS OF Therese Marie Westrup for the Master of Science in Speech Communication, with an emphasis in Speech Pathology, presented May 5, 1992.

Title: A Comparison of Two Kindergarten Screening Instruments in One Population.

APPROVED BY THE MEMBERS, OF THE THESIS COMMITTEE:

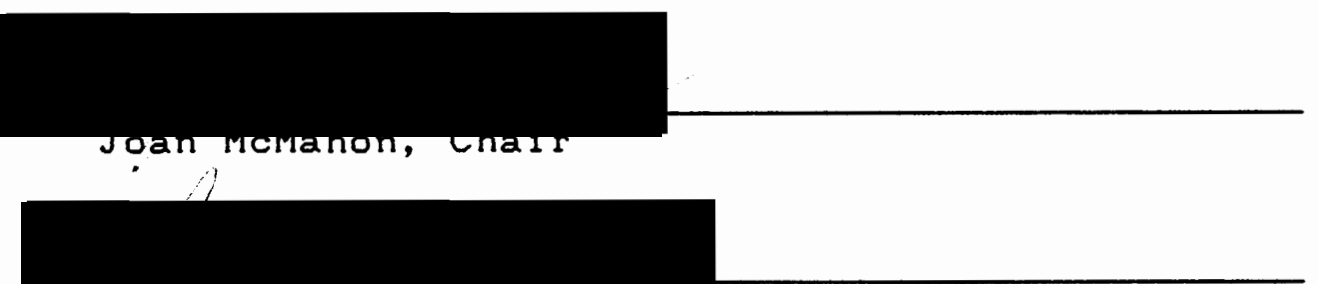
Mary T. Withers

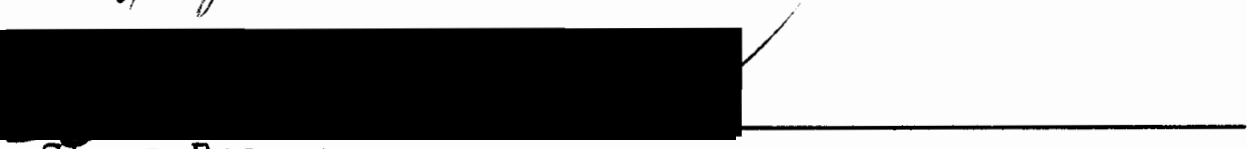

Steve Brannan

The purpose of this study was to compare thirty-two childrens' performances on the Daberon-2 Screening for School Readiness and the Early Screening Inventory (ESI), as well as determine whether there was a correlation between the tests. This study responded to the needs of the local Portland, Oregon area schools, some of which use these tests, to investigate the tests, and explore the possibility of using the shorter ESI over the longer Daberon. The reasoning behind the goal of the study was to determine that 
if the two tests showed a strong, positive correlation and identified the same children as needing further assessment, then perhaps the test which was shorter to administer could be used with confidence as a faster, but equally reliable pre-kindergarten screening tool. In other words, if a child "passes" the Daberon, one could assume that the child would most likely "pass" the ESI as well. Based on the results of this study, one can make this assumption with a reasonable amount of confidence.

The subjects in this study included 16 males and 16 females. All were preschool students, ranging in age from 4-6 to 5-6 with a mean age of 5-1 years. The subjects were given the two tests in a counterbalanced order, which also varied as to sex so that not all of one sex received one test first. The standard scores and whether or not each subject "passed" or "failed" each screen was determined. The correlation between the two tests was also determined.

The Pearson product moment correlation coefficient (Pearson r) was used to determine the degree of relatedness between the tests. A high positive correlation of . 73 was found between the Daberon and the ESI, with a shared variance $\left(\underline{r}^{2}\right)$ of $53.3 \%$.

In determining how the tests identify children needing further evaluation, a cut-off criteria of greater than one standard deviation below the mean for each screen was defined as a "fail," with scores at or above one standard 


\begin{abstract}
deviation below the mean categorized as a "pass." The results indicated that only 2 of the 32 children in this study showed a need for further evaluation. One child was identified by both the Daberon and the ESI, and one child was identified only by the ESI. The findings indicate that, based on these study results alone, one can reasonably assume that the ESI can be used in lieu of the similar, but longer, Daberon test. These results may have been affected by the small sample used for this study.
\end{abstract}


A COMPARISON OF TWO KINDERGARTEN SCREENING

INSTRUMENTS IN ONE POPULATION

by

THERESE MARIE WESTRUP

A thesis submitted in partial fulfillment of the requirements for the degree of

MASTER OF SCIENCE IN SPEECH COMMUNICATION:

with an emphasis in

SPEECH PATHOLOGY

Portland State University

1992 
TO THE OFFICE OF GRADUATE STUDIES:

The members of the Committee approve the thesis of

Therese Marie Westrup presented May 5, 1992.

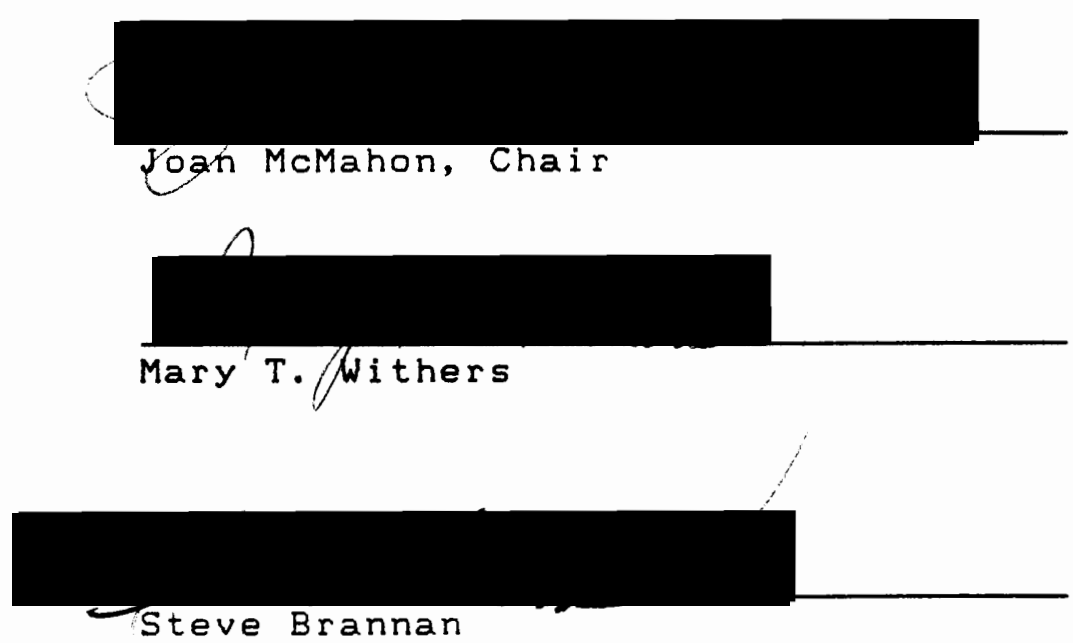

APPROVED:

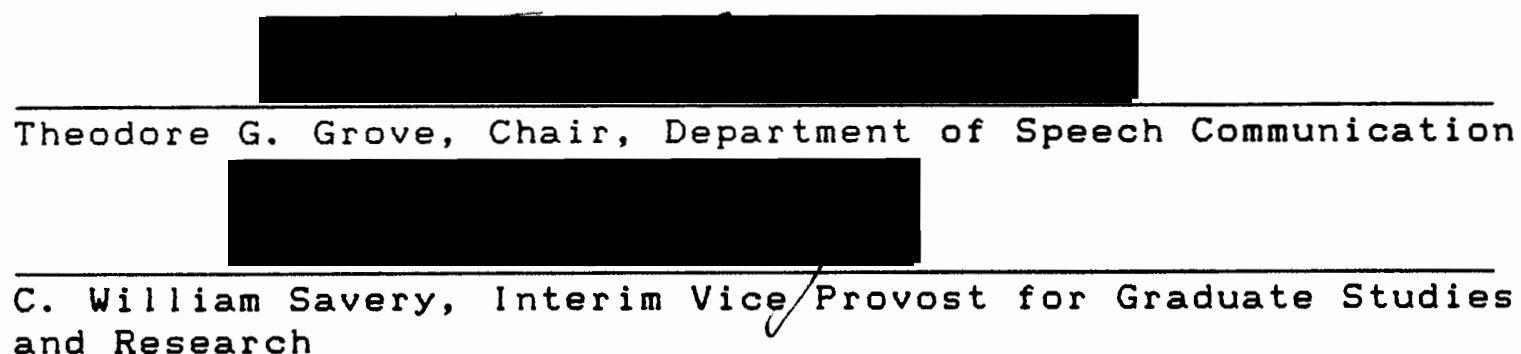




\section{ACKNOWLEDGMENTS}

I wish to express my gratitude and appreciation to Joan McMahon, my thesis and graduate advisor, for her support in this project. Her comments, suggestions, and creative ideas were essential to the completion of this thesis. They were also helpful for my peace of mind, which isn't easy to attain during graduate school.

I extend special thanks also to Mary T. Withers, my committee member whose fresh approach helped me formulate important points regarding the scoring and data analysis. In addition, Mary was extremely helpful in clinical and personal matters during graduate school. Her warm and caring personality traits are assets that do not go unnoticed among the graduate students at PSU, and she is well-1iked.

I thank the principals, teachers, parents, and children who were involved in allowing me to collect my data. They were all very supportive, enthusiastic, and helpful. Additional thanks go to Larry Gohl, my off-campus speech pathology mentor whose helpful advice, technical experience, and true faith in me kept me going.

To my parents, Marjorie and Dick Westrup, go my love and deep appreciation for their tremendous support and encouragement over the years.

I dedicate this thesis to my wonderful husband, 
Randal1, whose love, support, and confidence, made this research possible. 
TABLE OF CONTENTS

PAGE

ACKNOWLEDGEMENTS $\ldots \ldots \ldots \ldots \ldots \ldots \ldots \ldots \ldots \ldots \ldots \ldots \ldots$

LIST OF TABLES ......................... vi

LIST OF FIGURES $\ldots \ldots \ldots \ldots \ldots \ldots \ldots \ldots \ldots \ldots \ldots \ldots \ldots \ldots \ldots \ldots \ldots$

\section{CHAPTER}

I INTRODUCTIION $\ldots \ldots \ldots \ldots \ldots \ldots \ldots \ldots \ldots \ldots$

Statement of Purpose ............ 2

I I REVIEW OF THE LITERATURE ............. 4

Readiness Instruments ........... 4

Characteristics of exemplary tests... 8

Testing measures used in this study.. 11

II I METHODS ....................... 15

Subjects $\ldots \ldots \ldots \ldots \ldots \ldots \ldots \ldots$

Criteria for selection ........... 15

Instrumentation .............. 16

Testing Environment ........... 17

Procedures .................. 17

Research Design ............... 18

Scoring and Data Analysis ......... 18

IV RESULTS AND DISCUSSION .............. 20

Results ...................... 20

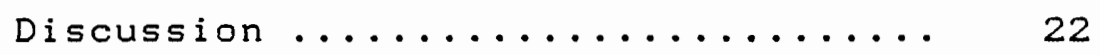

$\checkmark$ SUMMARY AND IMPLICATIONS ............. 29 


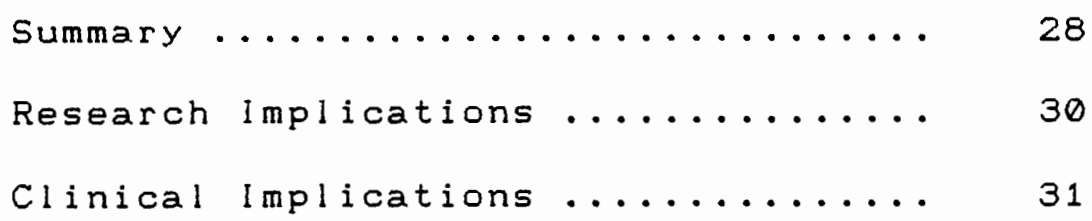

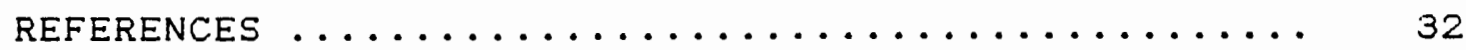

APPENDICES .......................... 34

A PERMISSION FORM $\ldots \ldots \ldots \ldots \ldots \ldots \ldots \ldots$

B DABERON-2 SCREENING FOR SCHOOL

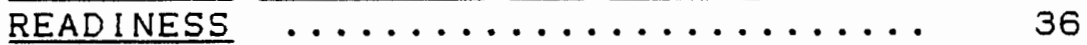

C EARLY SCREENING INVENTORY $\ldots \ldots \ldots$

D RAW SCORES OF TESTS ............ 43

E EVALUATION FORM ............. 45 


\section{LIST OF TABLES}

$\begin{array}{ll}\text { TABLE } & \text { Page }\end{array}$

I Ranges Among Raw Test Scores ............... 20

I I Mean Test Standard Scores and Standard

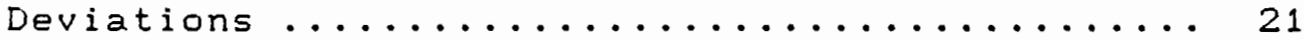

II Teacher Evaluation of Success in Current

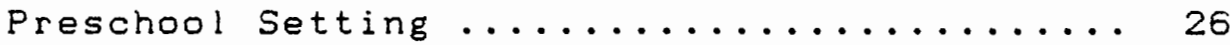

IV Subjects, Formal Test Results versus

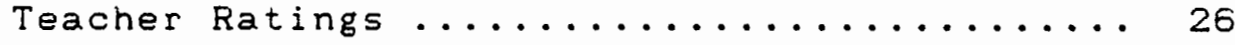




\section{LIST OF FIGURES}

FIGURE

PAGE

1. The shared variance among the Daberon-2 and the ESI, representing the amount of aspects common to the two tests ...... 22 


\section{CHAPTER I}

\section{INTRODUCTION}

Kindergarten screening tests are often used to identify children with potential basic concept and language limitations. The purpose of screening is to quickly identify children with speech/language problems while avoiding indepth testing of "normal" children. Presently, many school systems are attempting to identify kindergarten children who may be at $r$ isk using screening instruments supplemented with other procedures such as teacher referral. This has become more important than ever since Congress passed Public Law 99-457, which emphasizes the importance of early intervention in children at risk for learning (and other) disabilities, by extending all rights and protections afforded by Public Law 94-142 to children aged 3 to 5 (Salvia and Ysseldyke, 1991).

The Early Screening Inventory (ESI) (1983) and the Daberon-2 Screening for School Readiness (1991) are two well-known and preferred instruments currently in use as screening devices in the Portland Public Schools. The ESI is a developmental screening instrument which assesses a child's potential for success in school (Meisels \& Wiske, 1983). This screening test samples developmental 
accomplishments and is intended to identify children who are in need of further diagnostic evaluation (Meisels \& Wiske, 1983; Langhorst, 1989). The locally developed Daberon assesses learning readiness and is intended to sample the knowledge and skills of children as they begin school (Danzer, Gerber, \& Lyons, 1982).

Screening instruments with superior norms and standardization are preferred over those without such characteristics. The Daberon was standardized in 1980; published literature regarding its standardization quality is in the test manual of the Daberon-2 (Danzer, Gerber, Lyons, \& Voress, 1991). The ESI's normative information has been rated fair in the past, but new research and updated standardization are now available from the authors. If the two screens identified the same children as needing further assessment, then there would be a good rationale for using the screen which has the shorter administration time.

\section{STATEMENT OF PURPOSE}

The purpose of this study was to compare the performance of 32 children, between the ages of 4.6 and 5.6 , on two screening devices: the Daberon-2 and the Early Screening Inventory. The questions to be answered were: 1. Would there be a significant difference in their scores on the two tests? 2. What was the relationship between the two instruments, that is, the extent to which the scores 
could be statistically correlated?

The first question investigated whether there would be a significant difference in the number of children who "passed" or "failed" the two screening tests. The dependent variable in this question was the standard test score of each screening instrument. This variable was recorded for each student and then the two results were compared. The independent variables were the two screening instruments.

The second question sought to determine the statistical correlation between the two screening instruments. For this question, the independent variables were the two tests, and the dependent variables were the scores between the two tests. 
CHAPTER II

REVIEW OF THE LITERATURE

READINESS INSTRUMENTS

The purpose of school readiness testing is to assess a child's existing knowledge and skills so that direction in what needs to be taught can be provided. Also, information on the ability levels of groups of students is supplied so that school policy decisions on curriculum planning is made available (Langhorst, 1989). The content of a readiness instrument should be judged in terms of how useful the results are in providing information about specific areas which should be addressed for a particular child (Langhorst, (989).

Readiness Testing and Academic Achievement

Many studies in the literature show a correlation between readiness testing and later school achievement. Ilg, Ames, Haines, and Haines (1978) performed a longitudinal study examining several factors related to school readiness. The researchers examined their original group, tested in kindergarten, to determine how each had placed in the sixth grade. The sixth grade group had been divided, on the basis of general abilities and school performance, into 4 groups, 
with the most excellent students in Group 1, and the least excellent in Group 4. Sixty-seven percent of the children who had been considered "ready" were found to be in Group 1. Of those who were originally found to be "unready" or "questionable", $6 \%$ were in Group 1, $47 \%$ were in Group 2, 35\% were in Group 3, and $12 \%$ were in Group 4, or had only advanced to the fifth grade level.

A study by Gullo, Clements, and Robertson (1984)

examined how well the McCarthy Screening Test (MST) (1978) and the Metropolitan Readiness Test (MRT) (1976) were able to predict readiness at the end of kindergarten, and academic achievement at the end of first grade. Eighty-eight children were screened upon entering kindergarten with the MST. The MRT was administered at the end of kindergarten. As a measure of achievement the scott and Foresman Achievement Test (SFAT) (1973) was given at the end of first grade. The results of the study indicate that the MST significantly predicted children's scores on the MRT and the SFAT. In addition, the MRT was a significant predictor of the SFAT, indicating that this readiness test was an important indicator of future academic success as measured by the SFAT.

\footnotetext{
Telegdy (1977) examined the effectiveness of selected readiness tests to predict first grade success. Four readiness tests were administered to 56 children at the end of their kindergarten year. One year later, the children
} 
were reassessed with two standardized achievement tests. In this study, the best predictors of school achievement were the MRT and the Screening Test of Academic Readiness (STAR) (1966). The other two readiness tests, namely the First Grade Screening Test (FGST) (1966) and the Bender Gestalt Test (BGT) (1937) were found not to have good predictive validity in terms of first grade achievement. An interesting sideline conclusion in the research was noted. Of the skills measured by the various readiness tests, the "letter knowledge" turned out to be the most predictive component of actual first grade achievement. Telegdy (1977) also concluded that teacher predictions were efficient predictors of first grade achievement; he suggested that these predictions can complement formal tests.

The McCarthy Scales of Children's Abilities (MSCA) (1972) is a norm-referenced test which measures cognitive ability for children 2-6 to 8-6 (Keith, 1985). Harrison (1973) administered this test to 65 first grade children. Nine months later the Metropolitan Achievement Test (1970) was given to determine whether the MSCA could serve as a good predictor of first grade achievement. One subtest of the MSCA, the McCarthy General Cognitive Index, emerged as a significant predictor of achievement in multiple regression analysis.

Another aspect in the arena of children's academic achievement is the concept of reading. Success or failure 
in the early grades depends on a child's ability to learn to read (Randel, Fry, \& Ral1s, 1977). Randel et al. (1977) conducted a study to compare the predictive effectiveness of the $\mathrm{ABC}$ Inventory (1965), a preschool screening device, and the Metropolitan Readiness Test (MRT) which is a widely used reading-readiness test. The purpose was to assess the effectiveness of the two instruments in predicting first-and third-grade reading achievement. They found that the MRT, when using a middle-class sample of kindergarten children, was a good predictor of both first-and third-grade reading performance, with the highest predictive validity occurring at the third grade level.

Teacher Referral and Testing Instruments

Teachers' judgments are frequently used as the criteria for evaluating the validity of testing instruments (Langhorst, 1989). Thus it is pertinent to ask whether formal assessment tools are useful to teachers. According to Langhorst (1989), the type of information provided by formal readiness testing is useful to teachers because it provides them with specific instructional planning ideas. In addition, the instruments provide a way for teachers' observations to be structured so that the same information is obtained consistently for all children (Langhorst, 1989).

Bolig and Fletcher (1973) performed a study with kindergartners in North Pennsylvania School District, Lansdale, Pennsylvania, which compared the Metropolitan 
Readiness Test (MRT) as a predictor of first grade success to teacher judgments predicting the same students' first grade success. First grade success was defined as either a score on the Stanford Achievement Test (SAT) or a rating made by the teacher observing the student's first grade performance. The results showed that the MRT as a predictor of first grade success was as good or better than the ratings of teachers on the six skills which the MRT measures (Bolig \& Fletcher, 1973).

\section{CHARACTERISTICS OF EXEMPLARY TESTS}

Speech-Language pathologists, teachers, psychologists and other professionals are often in positions that require the testing of individuals for the purposes of evaluation or assessment in a particular area. Concern about the technical quality of tests or screening measures is based on an awareness that these instruments can be very powerful, useful tools when used correctly. Conversely, poor-quality tests can have damaging consequences or, at a minimum, provide the examiner with useless or misleading information (Walsh \& Betz, 1985).

For a test to be considered "good," or of high-quality, it must possess certain characteristics. These psychometric characteristics can be built into tests by sound and creative test construction (KIine, 1986). The first requirement for a good test is reliability. An instrument 
is said to be reliable if it is consistent, stable, replicable, and repeatable (Walsh \& Betz, 1985). The more repeatable a test is, the greater will be its reliability. In psychometrics, there are two types of reliability. The first is self-consistency. For a test to measure what it claims to measure, it must be internally consistent. As KIine (1986) stated, "If part of the test is measuring a certain variable, then the other parts, if not consistent with it cannot be measuring that variable" (p. 2). Test-retest reliability is the second type, and is also known as "stability" (Walsh \& Betz, 1985). It is essential for a test to yield the same score for a subject on different occasions.

The second major characteristic of a good test is its validity (Kline, 1986). A test is valid if it measures what it claims to measure. If a test is designed to measure school readiness, and it measures something else, then it is not a valid test for readiness. There are various ways to demonstrate test validity. Concurrent validity is assessed by correlating the test with other similar tests that are known to have good validity. Predictive validity is a type of criterion-related validity, and is generally recognized as the most accurate way to judge validity (Murphy \& Davidshofer, 1988). According to Kline (1986), "To establish predictive validity of a test, correlations are obtained between the test given on one occasion and some later 
criterion" (p. 5). The problem with this type of validity is finding a relevant criterion with which to correlate it. Another type of validity which is meaningful in test construction is content validity. Content validity refers to how well an instrument tests the specific behaviors from which inferences will be drawn. For example, a test for school readiness should sample a pre-school child's level of functioning. This would include the ability to cope with the school environment physically, socially, and academically, without undue stress. Overall then, a testing instrument should demonstrate high performance, or validity, in carrying out its basic function (Lichtenstein \& Ireton, 1984).

A further characteristic of high-quality tests is good norms. Norms are sets of scores from clearly defined samples (Kline, 1986). Normative data indicates how individuals of various ages might be expected to perform on a given test (Shames \& Wiig, 1986). They are therefore essential to meaningful interpretation of the obtained data. The development and procedures for obtaining these scores constitutes the test standardization ( $K l$ ine, 1986). Norm-referenced standardized tests are available for both screening and diagnostic purposes. Screening tests typically bestow "cut-off" scores. If an individual's performance falls below the cut-off, further evaluation is warranted. A diagnostic or screening test that is poorly 
standardized may provide very limited useful information (Shames \& Wiig, 1986).

No one instrument will meet all the possible criteria that could be outlined for screening readiness assessment or developmental potential. The most important criteria is how useful the information will be in leading to beneficial changes in the educational development of a particular child (Langhorst, 1989).

\section{TESTING MEASURES USED IN THIS STUDY}

The Daberon-2 Screening for School Readiness (1991) was designed as a screening and prescriptive instrument. Thus it can provide information which is useful for the teacher in planning a given child's educational agenda. It is currently in use in Portland public schools. According to the manual, a high percentage of accurate responses indicates school readiness. This tool is not an all-inclusive test of a child's abilities. It is a screening device designed to sample the knowledge and skills of four-, five-, and six-year-old children as they begin school. It assesses various language skills, including knowledge of body parts, color and number concepts, functional use of plurals and prepositions, and the ability to follow directions. It also surveys general knowledge, gross motor development, and the ability to categorize (Hamilton, 1974). Information gained from this test may be used to identify future problem areas, 
the need for further diagnostic study, and information that needs to be taught in the classroom (Danzer et al., 1972). The Daberon may also be used for baseline purposes in assessing educational progress.

When the Daberon was first published in 1972 and put to use as a screening instrument, it lacked standardization and no mention of reliability or validity studies was made in the test manual. In 1980, the Daberon was standardized so that pre-school and school-aged children's functioning skills could be quantified. This provided data-based evidence of school readiness or nonreadiness, and also gave the instrument needed psychometric data. The sample size was 1,358 children, aged 2 to 9 years, with the majority falling in the 3.1 to 6.5 age range. The children tested were from 16 different states. National standardization such as this ensures a cross-section of curriculum and social patterns. An equivalency age score is obtained which denotes a child's level of school readiness. This level of readiness indicates how a child compares to other children of the same age in the standardization sample. The equivalency age score does not represent a mental age. Rather, it indicates where a given child's performance is compared to the other children in the standardization sample (Danzer et al., 1982).

The Early Screening Inventory (ESI) was designed to identify children who may have a learning difficulty or a 
handicapping condition that could affect their potential success in school (Meisels, Wiske, \& Tuvnan, 1984). This screening inventory is currently in use in Portland public schools. The instrument is administered individually and is composed of 30 items covering an age range of 4 to 6 years. The developmental areas examine visual-motor tasks which include fine motor control, eye-hand coordination, memory of visual sequences and ability to reproduce structures. Language, verbal reasoning, the ability to count and remember auditory sequences is also included. In addition, items which evaluate gross motor coordination and imitation of body positions are examined (Meisels, Henderson, Liaw, Browning, \& Ten Have, 1991).

The new standardization sample consisted of 2,746 children between the ages of 4-0 and 5-11. The sample characteristics were defined as being collected from 45 educational sites in 11 states, and consisted primarily of Caucasian children, with $34 \%$ being nonwhite. Fifty-five percent of the sample were middle to high SES, with 45 percent of low SES.

An important component of the ESI screening process includes the parent questionnaire. As part of a recent standardization study, the questionnaire was found to have moderate to high reliability (alpha $=.72$ ) with regard to its internal consistency (Meisels et al., 1991). When used in combination with the test itself, the specificity and 


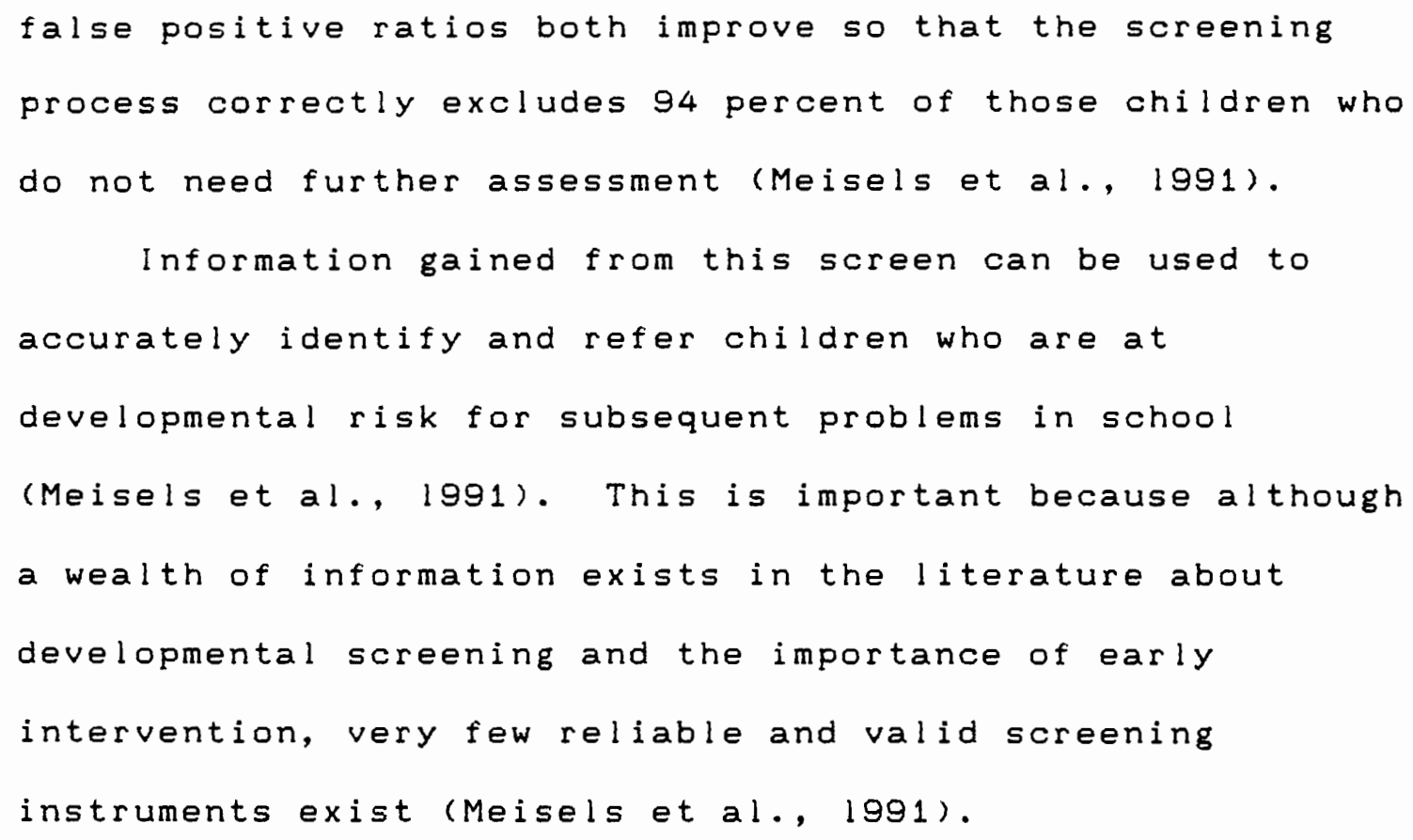


CHAPTER III

METHODS

SUBJECTS

Thirty-two children, ( 16 girls and 16 boys) enrolled in Portland, Oregon area preschools were chosen for this project. The age range was from 4-6 to 5-6 years. The children were assumed to be of normal intelligence based on teacher report.

\section{CRITERIA FOR SELECTION}

In order for a child to have been included in the study, the following criteria were met:

1. The child's parent signed a form giving permission for the child to take part in the study. (See Appendix A).

2. The child was able to respond to the items on the Daberon and the ESI. Specifically, the child understood English reasonably well, and possessed enough cognitive skills to attempt to respond appropriately.

3. The subject had not been exposed to or had not taken the ESI or the Daberon previously.

4. Each child passed a puretone audiometric screening test at $25 \mathrm{~dB} H \mathrm{HL}$ at frequencies of $500,1000,2000$, and 4000 $\mathrm{Hz}$. 
5. The child showed no obvious intel lectual deficits as judged by teacher observation and report.

\section{INSTRUMENTAT ION}

A portable Maico audiometer model \#MA-16 was used for the hearing screening.

The Daberon is comprised of 124 items appropriate for children aged 3 through 6 . Four and five year olds were the priority age groups in the standardization data. Various types of responses are required and include verbal responses to questions, color identification, counting, a working knowledge of prepositions, demonstration of gross and fine motor movements, copying figures, and placing items in an appropriate category. The test takes approximately 45 minutes to administer. (See Appendix $B$ ).

The ESI is appropriate for ages 4-0 to 6-0. It surveys abilities in speech, language, cognition, perception, and gross and fine motor skills. This test is comprised of 36 items and takes approximately 20 minutes to administer. (See Appendix $C$ ).

\section{TEST ING ENVIRONMENT}

Before formal testing, rapport was established through brief casual conversation. The environment during testing was a quiet, well-lit room at their preschool free from clutter and other people. The children were tested one at a 
time, seated at a table on the examiner's left side. The stimulus items were placed between the examiner and the subject. Items not in use were kept out of sight to avoid possible distraction. The room chosen was large enough to permit the evaluation of gross motor activities.

\section{PROCEDURES}

\section{Criteria Testing}

Once permission was granted for the child to take part in the study, the hearing screen was performed on each potential candidate. The child was tested at each of the frequencies previously mentioned.

\section{Test Administration}

During the formal test administration, verbal reinforcement such as "Good listening" was used intermittently. Both tests were administered in full, including the parent questionnaire on the ESI, and scored according to the respective manuals.

The ESI was administered according to the test directions in the manual. The test items are not arranged developmentally.

The tests were conducted by giving the hearing screen and one test on one day, and the other test on another day, with the testing instruments and the hearing screen all being presented within a 6-week period. To control for a learning effect, the order of test administration was 
counterbalanced. To insure that all of either sex was not administered a particular test first, the order of presentation to males and females was also counterbalanced.

\section{RESEARCH DESIGN}

This was a correlational study of two screening instruments. Such a design was appropriate for examining the question of the degree of relationship, if any, that exists between the Daberon-2 and the Early Screening Inventory.

\section{SCORING AND DATA ANALYSIS}

The standard scores of the Daberon-2 and the ESI were calculated according to the instructions presented by the respective test manuals. The information determined by scoring included the standard scores of the two instruments. (See Appendix E).

The research questions presented in the statement of purpose were analyzed using two different types of data analysis. The study sought to determine whether the same children in a given sample would require further assessment as determined by their results on the two screens. Thus, a reasonable pass/fail criterion for each screening device was designated by the investigator. A "failure" on the Daberon-2 was defined as a score that was greater than one standard deviation below the mean for a given age group. A "pass" 
was any score at or above 1.0 standard deviation below the mean. For the Early Screening Inventory, a failure included scores falling in the "rescreen" or "refer" range; these were scores lower than one standard deviation below the mean for each age range. A pass included all scores at or above one standard deviation below the mean.

The first question investigated whether the same children would pass or fail the two screens. To examine this, descriptive statistics were utilized.

The use of inferential statistics was appropriate for the second question, which examined the possible correlation between the two screening instruments. Thus the Pearson

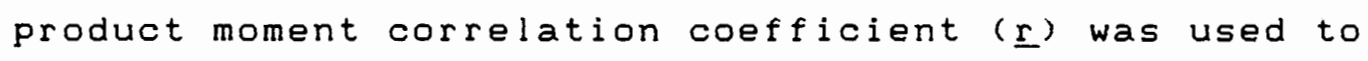
determine the degree of relationship between the devices. Also, the amount of shared variance between the tests was determined by calculating $r^{2}$. 


\section{CHAPTER IV \\ RESULTS AND DISCUSSION}

RESULTS

The purpose of this investigation was to compare the performance of 32 preschool children on the Daberon-2 with their performance on the ESI. The first question posed was: Would there be a significant difference in the number of children passing or failing the two tests? In order to answer this, the data were analyzed using descriptive statistics. The raw test scores appear in Appendix $F$.

The ranges of raw test scores and mean standard scores with standard deviations appear in Tables I and II respectively.

\section{TABLE I}

RANGES AMONG RAW TEST SCORES

= = = = = = = = = = = = = = = = = = = = = = = = = = = = = = = = = = = = = = = = = = = Scores DABERON-2 ESI

\begin{tabular}{lcc} 
High & 119 & 30 \\
Low & 75 & 11 \\
RANGE & 44 & 19 \\
\hline$n=32$ & &
\end{tabular}


TABLE II

MEAN TEST STANDARD SCORES AND STANDARD DEVIATIONS

= = = = = = = = = = = = = = = = = = = = = = = = = = = = = = = = = = = = = = =

Test

MS

SD

DABERON-2

ES 1
107.68

9.53

25.53

3.86

The second question in this study examined the statistical correlation between the ESI and the Daberon. The correlation coefficient between the two tests was .73 , indicating a high positive relationship. This Pearson $\underline{r}$ is statistically significant beyond the .001 level of confidence. Additionally, the amount of shared variance between the tests was determined by computing $\underline{\underline{r}}^{2}$. Shared variance identifies the percentage of aspects common to the two tests being correlated.

In Figure 1, the area which is shaded represents the amount of shared aspects between the tests, with the white areas showing the amount which is not accounted for. The percentage of shared variance between the Daberon-2 and the ESI was 53.3 


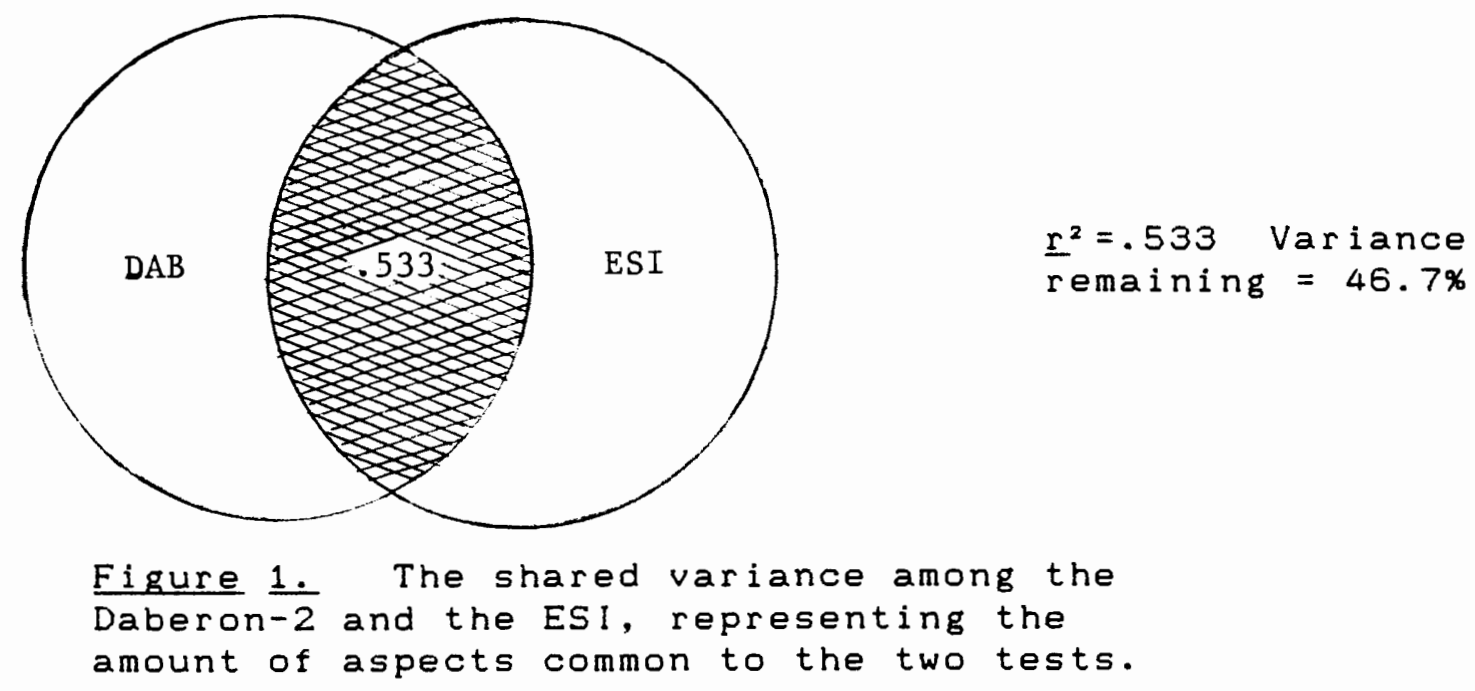

DISCUSSION

The basic assumption made in this study was that the Daberon and the ESI were approximately equal in terms of standardization. Both had substantial population samples and very good reliability and validity data. Compared to other similar preschool screens, these two tests had the best psychometric properties of those the author reviewed.

The first question of this study asked whether there would be a significant difference in the number of children passing the two screens. Of the 32 children, 30 passed both the ESI and the Daberon, one failed both the screens, and one failed the ESI but passed the Daberon. This one exception (subject \#14) can most probably be accounted for by factors not inherent in the tests, or to random chance, but rather had to do with the abilities and experience of that particular child. It is also possible that one of the tests could have given a false positive result. If that was 
the case, the child would be falsely identified as needing further evaluation, when in fact this may not be necessary. This would require additional unnecessary work for the test administrator, who would be obliged to test the child further, and perhaps communicate the apparent problem with teachers, parents, and other faculty members. It is also possible that one of the tests failed to select out a child in need of further assessment. This child could therefore remain undetected until some later time in school when problems may become apparent. Molnar (1984) relates that the early identification of learning problems is important in the development of educational programs. He further asserts that if a student's capacities and limitations are identified early, effective intervention programs can be implemented. If a large percentage of preschoolers had been left undetected by one of the tests, this researcher would not support the use of that test.

To summarize the data, $93.7 \%$ of the sample children passed both the screens, $3.2 \%$ failed both tests, and $3.2 \%$ failed one but not the other. Thus, there was not a significant difference in the number of children who passed or failed both screening instruments.

Since all of the children but one passed or failed both of the screens, there is a good basis for using the shorter ESI test. It is relatively inexpensive, quick to administer, and currently in use in the area. It has good 
standardization data, and when it was compared to another valid, standardized test (the Daberon), virtually the same number of children were identified. Thus there is good reason to use the ESI over the Daberon which takes much longer to administer.

The correlation coefficient determined between the Daberon and the ESI was. 73 , which is significant beyond the .001 level of confidence. This high correlation indicates a close association, or a high index of relationship, between the two tests. As an aside, it is interesting to note that some of the test items are identical on both screens. The high statistical correlation lends confidence to the assumption that the two tests are comparable, and that a high (or low) score on one test means a high (or low) score on the other.

The amount of shared variance between the tests was determined by calculating $r^{2}$. The shared variance was high, indicating that $53.3 \%$ of aspects were common to the two tests.

In addition to screening instruments, teachers have first hand experience in determining a particular child's potential for learning and their readiness for the school environment. Formal, standardized testing does not take into consideration all of the factors that are involved in determining a child's readiness to participate in a school setting. Although not a part of the questions examined by 
this study, the investigator wanted to incorporate the importance of teachers' opinions regarding childrens' apparent success, or lack of it, in a preschool setting, and correlate this with the standardized test results. An independent criterion in the form of a teacher evaluation was compared with the two tests to determine if this would correlate with the results on one or both of the test instruments. The subjective evaluation was completed by the pre-school teacher and required a judgement as to each child's current preschooi success. Each child was rated as "successful," "unsuccessful," or "somewhat successful" in their current preschool setting. (See Appendix E). Descriptive statistics were used to analyze the relationship between the standardized tests and the teacher evaluations. As can be seen in Table III, the teacher evaluations of each child's apparent success in his or her current preschool setting correlated fairly well with the results of the formal tests.

Twenty-eight subjects were rated by the teacher as "successful." Four were rated "somewhat successful," with all of these passing both the Daberon and the ESi. Only one subject failed both the screens; she received a teacher evaluation of "successful". One child failed the ESI, but passed the Daberon, and received a "successful" rating by the teacher. None of the children were rated as "not successful" by the teachers. 
TABLE III

TEACHER EVALUATION OF SUCCESS IN CURRENT PRESCHOOL SETTING

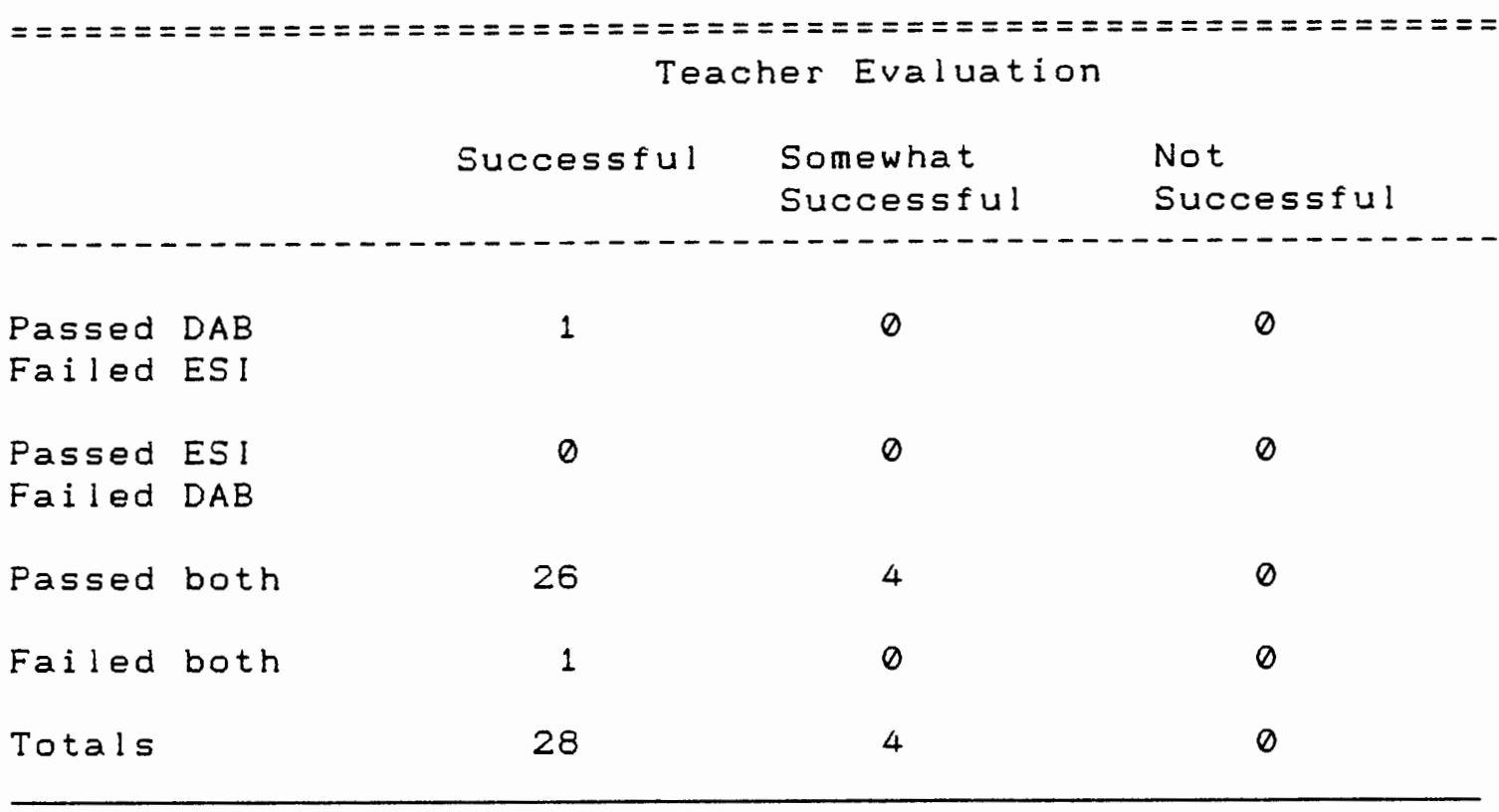

Table IV shows that the teacher evaluations correlated well with the standard test results of both the Daberon and the ESI.

TABLE IV

SUBJECTS' FORMAL TEST RESULTS VERSUS TEACHER RATINGS

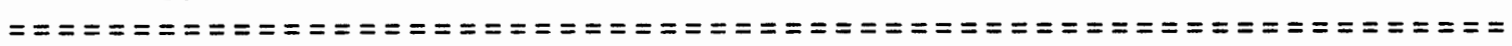
Teacher rating of Daberon ESI "successful" or "somewhat successful"

Pass

31

30

32

Fail

1

2

0

$n=32$

In this investigation, all but 1 (of 32) teacher's 
evaluations correlated with how a particular child performed on the standardized tests. However, there were 4 children who were rated "somewhat successful" and all of these passed both of the formal tests. One child who failed both the screens was rated "successful." Informal probing on the author's part as to the reason a child might be rated "somewhat successful" versus "successful" revealed that teachers considered several factors before rating a given child. Emotional and psychological factors, social skills, and behavioral aspects were included in their decisionmaking process. These factors are not measured by either of the standardized tests, but are obviously important in deciding how well a particular child is doing in school. Another possible reason for the one subject failing both formal tests and yet receiving a "successful" rating is that the evaluator's skills in this area may be lacking. Not all teachers make sound judgments all of the time. For the most part, the respective teachers' judgements of the children's success were consistent with the results of both of the screens, and their evaluations served to validate the tests with which they were consistent.

The investigator realizes the limitations of the methods used to collect the preceding data. In retrospect, the criteria for the subjective teacher evaluation should have been more specific. No criteria were attached to the rating, other than the child was considered to have a 
"normal level of intelligence," thus eliminating this as a factor. Perhaps a rating system which listed specific criteria used to evaluate each subject would have been more appropriate. 


\author{
CHAPTER V \\ SUMMARY AND IMPLICATIONS
}

SUMMARY

The Early Screening Inventory and the Daberon-2

Screening for School Readiness are two preschool screening instruments that are well-standardized and currently in use in Portland public schools. The purpose of this study was to determine whether the same number of children would pass or fail the two tests, as well as to determine the relationship between the instruments. If there was a strong positive correlation between the instruments and virtually the same number of children passed or failed both the tests, the test which is shorter to administer could be used with confidence as a reliable instrument for screening preschoolers. Based on the results of this study, this is a valid assumption. The subjects in this study included 16 females and 16 males. All were preschool students, ranging in age from 4-6 to 5-6. The children were given the two tests in counterbalanced order. The standard scores, standard deviations, and ranges were determined for both tests. The degree of relatedness between the tests was determined using the Pearson product moment correlation coefficient (Pearson $\underline{r}$ ). A strong positive correlation of 
.73 was found between the tests. Shared varlance ( $\underline{x}^{2}$ )

between the tests was $53.3 \%$.

In determining how the tests identify those needing

further evaluation, a pre-designated cut-of of less than

one standard deviation below the mean for each test was

considered a "fail," with those above this cut-orf being

considered a "pass." The results indicated that only 2 of

the 32 children failed. One child was identified by both

tests, and the other was identified only by the ESI. These

results indicate that, at least based on this study alone,

results on the Daberon can be used as a predictor of results

on the ESI, and that therefore the ESI should be used since

it is a much shorter test.

RESEARCH IMPLICATIONS

Some research and other possible implications of this study are noteworthy. Since these two tests were found to be related, (that is, the Pearson product moment coefficient was fairiy high) this study provides additional validity to the Daberon and the ESI as screening instruments. Whenever two tests are compared, and significant numbers are obtained statistically, it serves to validate a test (Nordlund, 1989). Further research could compare the ESI and Daberon to other standardized kindergarten screens, and serve to either validate them or provide data that questions their validity. 


\section{CLINICAL IMPLICATIONS}

The important clinical implication is that the first question was supported, that is, there was not a significant difference in the number of children who were identified by both instruments. This number (1) was small, so that the use of the ESI as a kindergarten screening device would be encouraged among speech-language pathologists who are screening in schools. Mass screenings of kindergartners take place in most, if not all, of the Portland Public Schools. It is important to accomplish this in a timely manner, and with as ittie classroom disruption as possible. The ESI is shorter to administer, correiates weil with the Daberon, and has good standardization data. Also, knowledge of

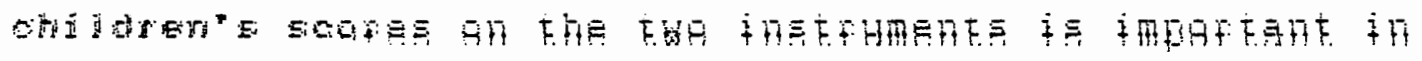
clinical decisions regarding possible remediation and intervention for a particular child or group of children. 


\section{REFERENC.ES}

Bolig, J., \& Fletcher, G. (1973). The MRT vs. ratings of kindergarten teachers as predictors of success in first grade. Educational Leadership, 30, 637-689.

Danzer, V., Gerber, M., \& Lyons, T. (1972). Daberon: A screening device for school readiness. Portland, OR: Daberon Research.

Danzer, V., Gerber, M., \& Lyons, T. (1982). Daberon revised: A screening device for school readiness. Portland OR: Daberon Research.

Danzer, V., Gerber, M., \& Lyons, T., with Voress, J. K., (1991). Daberon-2: Screening for school readiness. Austin, TX: Pro-Ed.

Gul1o, D., Clements, D., \& Robertson, L. (1984). Prediction of academic achievement with the McCarthy Screening Test and Metropolitan Readiness Test. Psychology in the Schools, 21, 264-269.

Hamilton, P. A., (1974). Validation of the oregon School Entrance Speech Screening Test. Unpublished thesis. Portland State University, Portland, OR.

Harrison, P. L. (1973). Mercer's Adaptive Behavior Inventory, the McCarthy Scales, and dental development as predictors of first grade achievement. Journal of Educational Psychology, 73, 78-86.

Ilg, F., Ames, L., Haines, G., \& Haines J. (1978). School readiness: Behavior tests used at the Gesell Institute. NY: Harper \& Row.

Kline, P. (1986). A handbook of test construction. New York: Methuen \& Co. Ltd.

Langhorst, B. H., (1989). Assessment in early childhood education: A consumer's guide. Northwest Regional Educational Laboratory. Portland, OR. 
Liechtenstein, R. \& Ireton, H. (1984). Preschool screening: Identifying young children with developmental and educational problems. Orlando: Grune \& Stratton, Inc.

Meisels, S., \& Wiske, M., (1983). Early Screening Inventory. Hagerstown, MD: Teachers College Press.

Meisels, S., Wiske, M., \& Tiunan, T. (1984). Predicting school performance with the early screening inventory. Psychology in the Schoois, 21, 25-33.

Meisels, S., Henderson, L., Liaw, F., Browning, K., \& Ten Have, T. (1991). New evidence for the effectiveness of the Early Screening lnventory Unpublished manuscript, University of Michigan, University of North Carolina at Chapel Hill, \& Educational Testing Service.

Molnar, G. (1984). kindergarten screening: A tool for early intervention of learning eroblems. Paper presented at the meeting of the National Association of School

Psychologists, Philadelphia, PA.

Murphy, K. \& Davidshofer, C. (1988). Psychological testing: Principles and applications. Englewood Cliffs, $\mathrm{NJ}$ : Prentice-Hall.

Nordlund, A. (1989). Correlation of preschoolers' performance on three language comprehension tests. Unpublished thesis, Portland State University, Portland, OR.

Randel, M., Fry, M., \& Ralis, E. (1977). Two readiness measures as predictors of first-and third-grade reading achievement. Psychology in the Schools, 14, 37-41.

Salvia, J., \& Ysseldyke, J. (1991). Assessment ( $5^{\text {th }}$ ed.). Boston: Houghton Miffi in Company.

Shames G., \& Wiig, E. (1986). Human communication disorders ( $2^{n d}$ ed.). Columbus: Charles E. Merrill Publishing Co.

Telegdy, G. (1977). The effectiveness of four readiness tests as predictors of first grade academic achievement. Fsychology in the schools, 12, 4-11.

Walsh, B., \& Betz, N. (1985). Test and assessment. Englewood Cliffs, NJ: Prentice-Hall, Inc. 
APPENDIX A

PERMISSION FORM 
Dear Parent,

As a graduate student at Portland State University, I am currently investigating two different Kindergarten Screening Tests. The Daberon-2 is a kindergarten readiness test, and the Early Screening Inventory tests developmental abilities. A comparison study is being made whereby a child will be given both tests. I would appreciate your permission to include your child in this project.

The testing will involve the instruments mentioned above and a hearing screening. In addition, the teacher will be asked to provide input regarding your child's success in his/her current pre-school setting. Your child's participation in this study will present no physical or psychological risks. All data obtained during the course of study will remain confidential. Published material will not reveal the name of your child.

If you decide to allow your child to participate in this study, please fill out the appropriate portion of this form. Please return your reply to your child's teacher/daycare worker as soon as possible. If you choose to allow your child to participate, you are free to withdraw him/her from the study at any time without affecting services provided at his/her school or from Portland State University. This study will benefit children with language, physical, and/or cognitive delays by providing new information to the speechlanguage-pathologists working with them.

I have read and understand the above statements and I agree to let my child participate in this study.

DATE

PARENT

PHONE \# :

Your child's testing for this study will be conducted at his or her pre-school. The results will be available upon request.

The child must be between 4.6 and 5.6 years old. Child's Birthdate:

If you experience problems that are the result of your participation in this study, please contact the secretary of the Human Subjects Research Review Committee, Office of Grants and Contracts, 303 Cramer Hall, Portland State University, 725-3417. For more information about this study, you may contact Therese westrup at 282$5270(H)$ or $725-3602$ (School). 
APPENDIX B

DABERON-2 SCREENING FOR

SCHOOL READINESS 


\title{
DABERON
}

\section{A Screening Device for School Readiness}

\author{
Virginia A. Danzer, M. Ed. \\ Theresa M. Lyons, M. A. \\ Mary Frances Gerber, M. Ed.
}

The Daberon Screening Device for four, five and six-year-old children surveys knowledge of body parts, color and number concepts, functional use of prepositions and plurals, the ability to follow directions, general knowiedge, visual perception, gross motor development, and the ability to categorize. A high percentage of accurate responses indicates school readiness. inaccurate items may indicate future problem areas, the need for further diagnostic and prognostic study. information that needs to be taught, and/or needed medical or psychological attention.

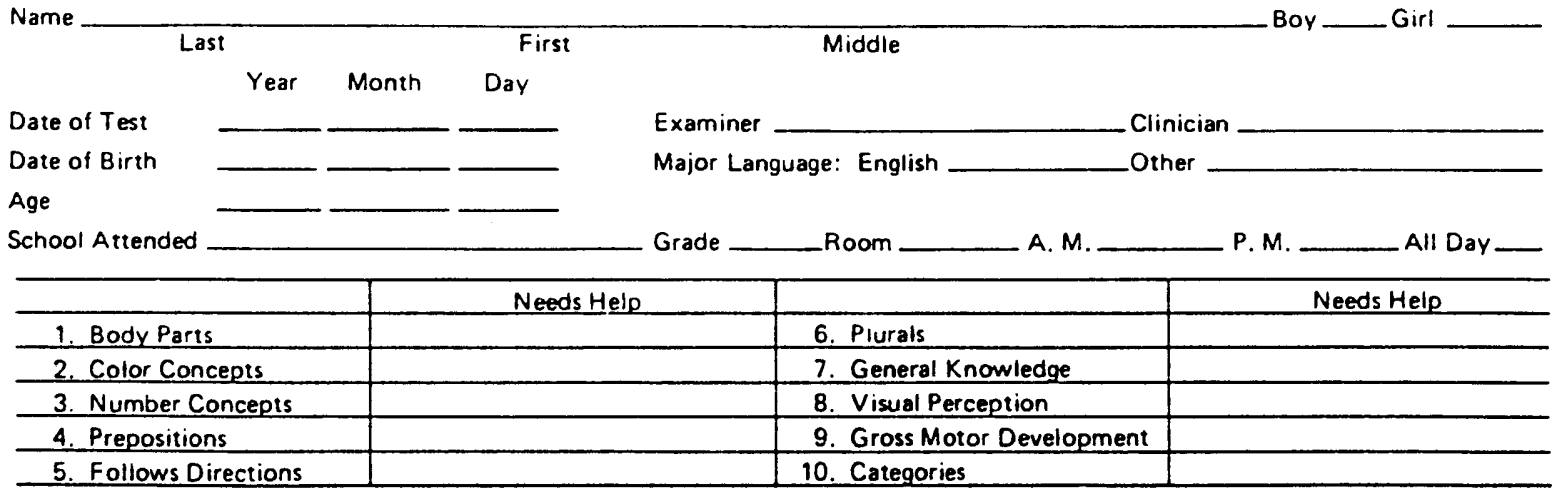

Scoring: $\mathbf{R}=$ right or correct response: $W=$ wrong or incorrect response; $N=$ no response: 1 * inappropriate response (i.e., child may echo examiner, response not relevant to question, etc.) Instructions to examiner are enclosed in parentheses and should not be verbalized to child. Unintelligible response . Place star in I column on test form.

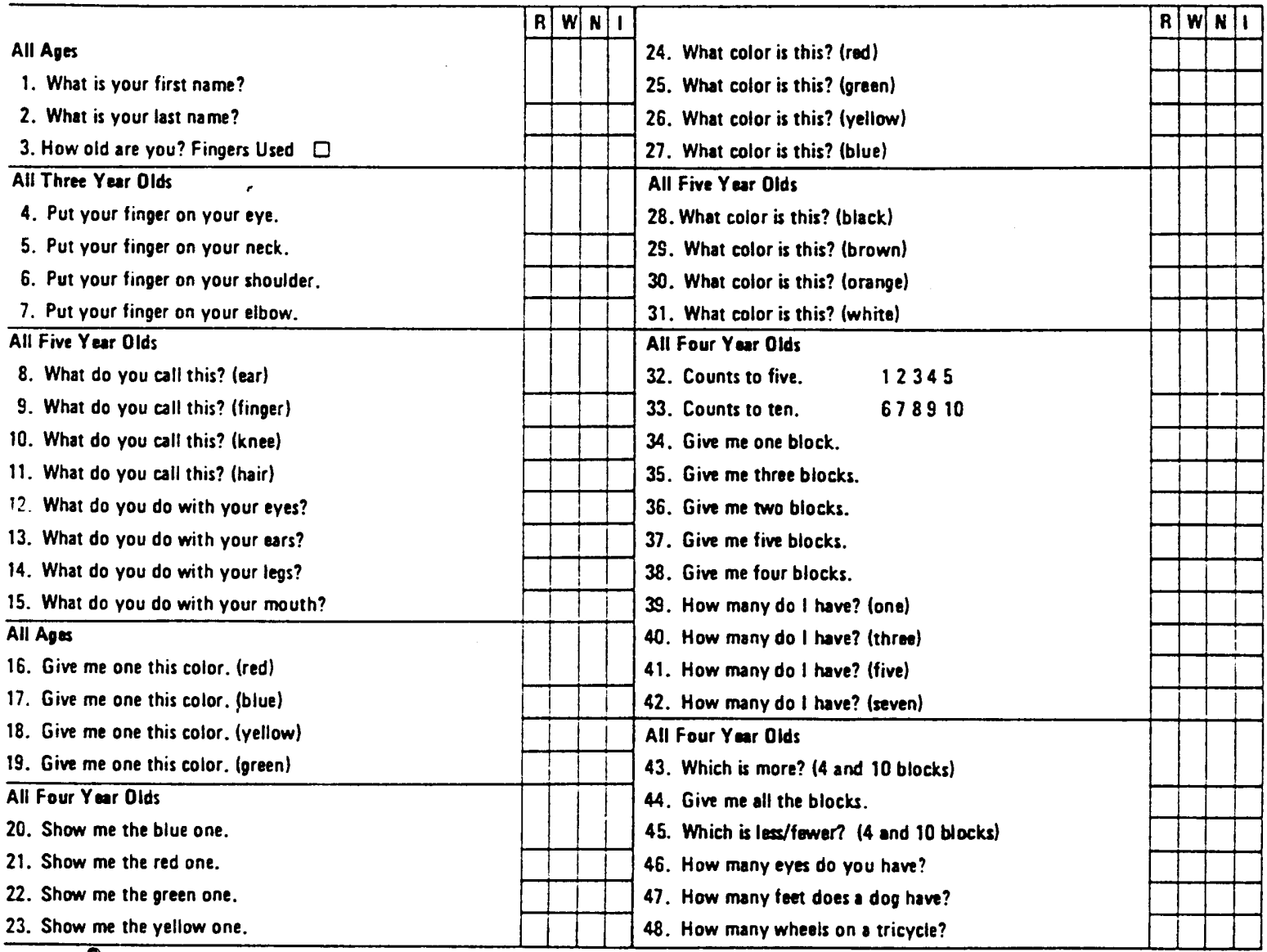

Copyright 1972 by Daberon Research All rights reserved. 
All Five Yaar Olds

49. Put your finger on the one in the middle. (Picture 1)

50. Put vour finger on the fust one. (Picture 2)

51. Put your finger on the last one.

52. Put your finger on the second one.

53. Put your finger on the next to the last one. All Three Year Olds

54. Put the car in the box.

55. Put the airplane under the box.

56. Put the car behind the airplane.

57. Put the car on the box.

58. Put the car in front of the airplane.

59. Put the airplane next to the box.

All Three Year Olds

60. Stand up.

61. Sit down.

62. Stand up and walk forward.

63. Walk backward.

64. Raise your hand.

65. Walk around your chair and sit down.

66. Clap your hands, take the ball, and go to the door.

67. Show me the boys. (Picture 2)

68. Put your hands on the table.

69. Show me the wings. (airplane)

70. What's in the box? (cars)

71. What are these? (blocks)

72. What's in my hand? (buttons)

All Five Year Olds

73. Which is bigger, a tree or a flower?

74. Which is slower, a car or a bicycle?

75. Which is heavier, a stove or a sock?

76. Where do we buy gas?

77. Where would you find a cow?

78. Whom do you go to when you are sick?

79. What does a fireman do?

80. What does a dentist do?

All Four Year Olds

81. What do you do when you are sleepy?

82. What do you do when you are hungry?

83. What do you do when you are thirsty?

84. What are books for?

85. What is a stove for?

86. What is a key for?

87. What is an umbrella for?

88. What are houses for?

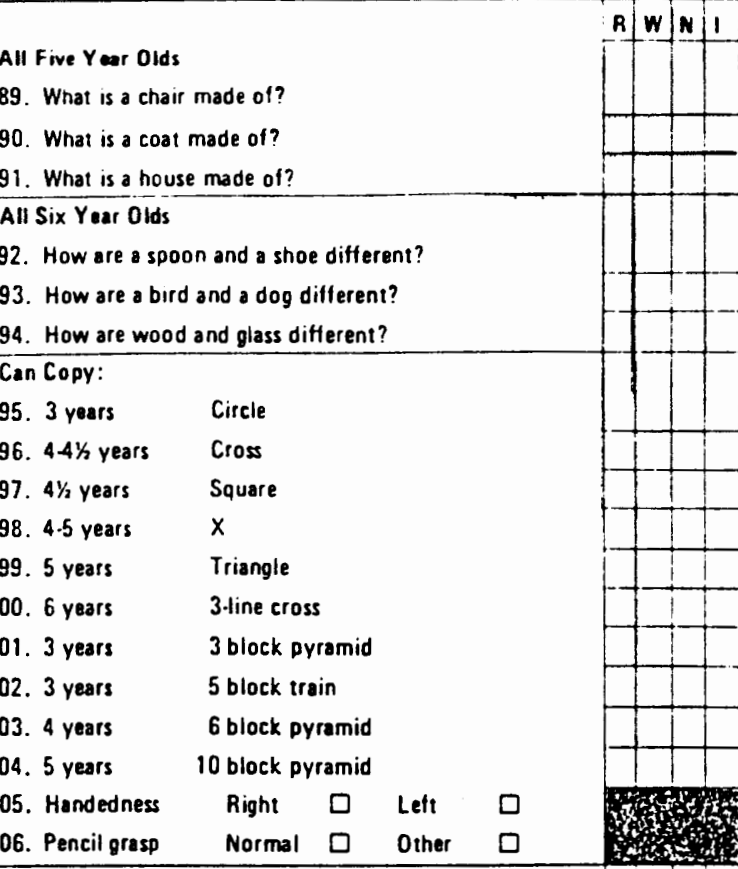

107. Stands on one foot. 18 seconds)

108. Hops with both feet together. $(7$ or 8 hops)

109. Hops on right foot. (3 or 4 hops)

110. Hops on left foot. (3 or 4 hops)

111. Gallops. (15 feet)

112. Skips. (15 feet)

113. Sitting position catches rolied ball.

114. Sitting position colls ball to examiner.

115. Standing position catches bounced ball.

116. Standing position bounces ball to examiner.

117. Standing position throws ball. (overhand)

118. Standing position catches ball.

All Five Year Olds

Put these pictures where they belong.

119. Food

120. Clothing

121. Animals

What are these things called?

122. Food

123. Clothing

124. Animals

Date: Total Correct

Date: Total Correct

Date: Total Correct

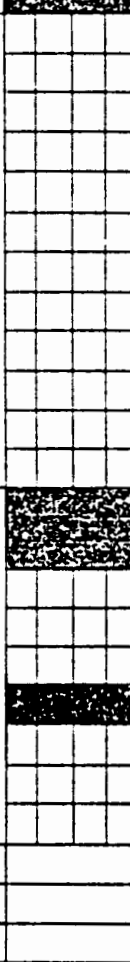

Comments: 
APPENDIX C

EARLY SCREENING INVENTORY 


\section{Early Screening Inventory}

S. I. Meisels and M. S. Wiske

\section{SCORE SHEET}

Child's name

Date of screcning

Date of birch

Current age

'

month

\section{Tu}

din

Scx: male

female

Schoos

Teacher

Screener

Parent questionnaire completed? yes ___ no _-_

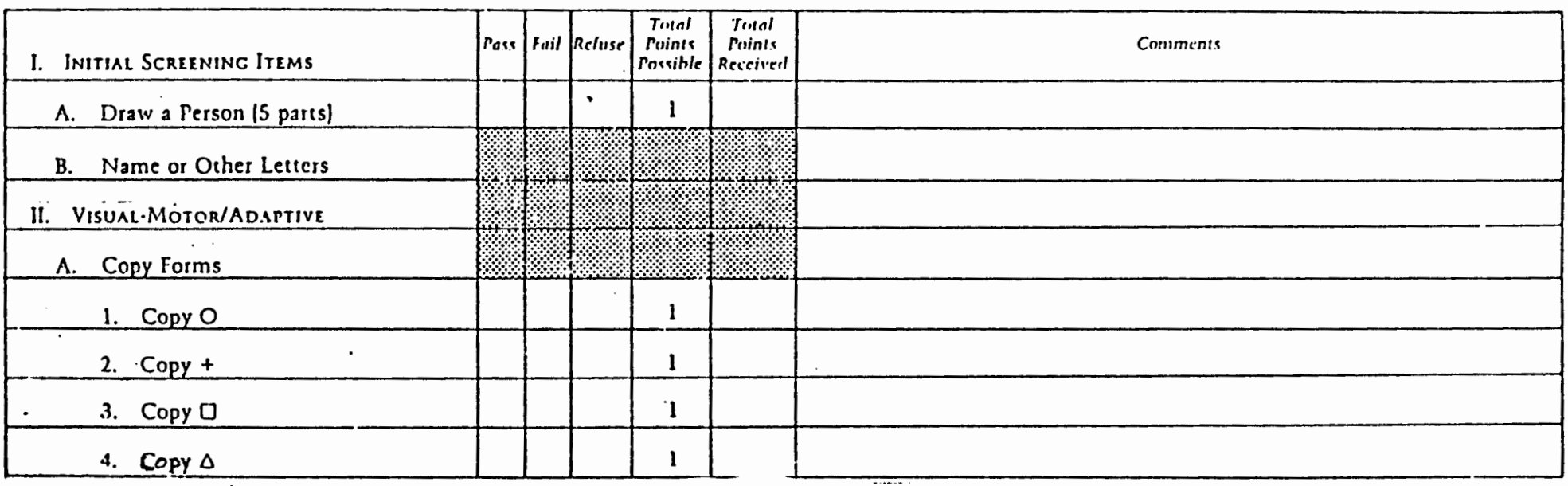

Copyrighe $C 1983$ by Teachers College, Columbia University. All rights reserved. Na par of th:s publication may be reproducce or transn:itred in any form or by any means, clecironic or mechanieal, inciuding photocopy, or any information storage and retrieval system, without ix rmission In Part III, C, Verbai Reasonine opposite analogies 1, 3, and 4 and thelr scoring are from L. M. Terman \& M. A. Mierrill, Stanford-Bince Intelligence Seale (Boxton: Houghton Miffin, 19731, pp. 136, 148. Reprinted by permission of The Riverside Publishing Company. 


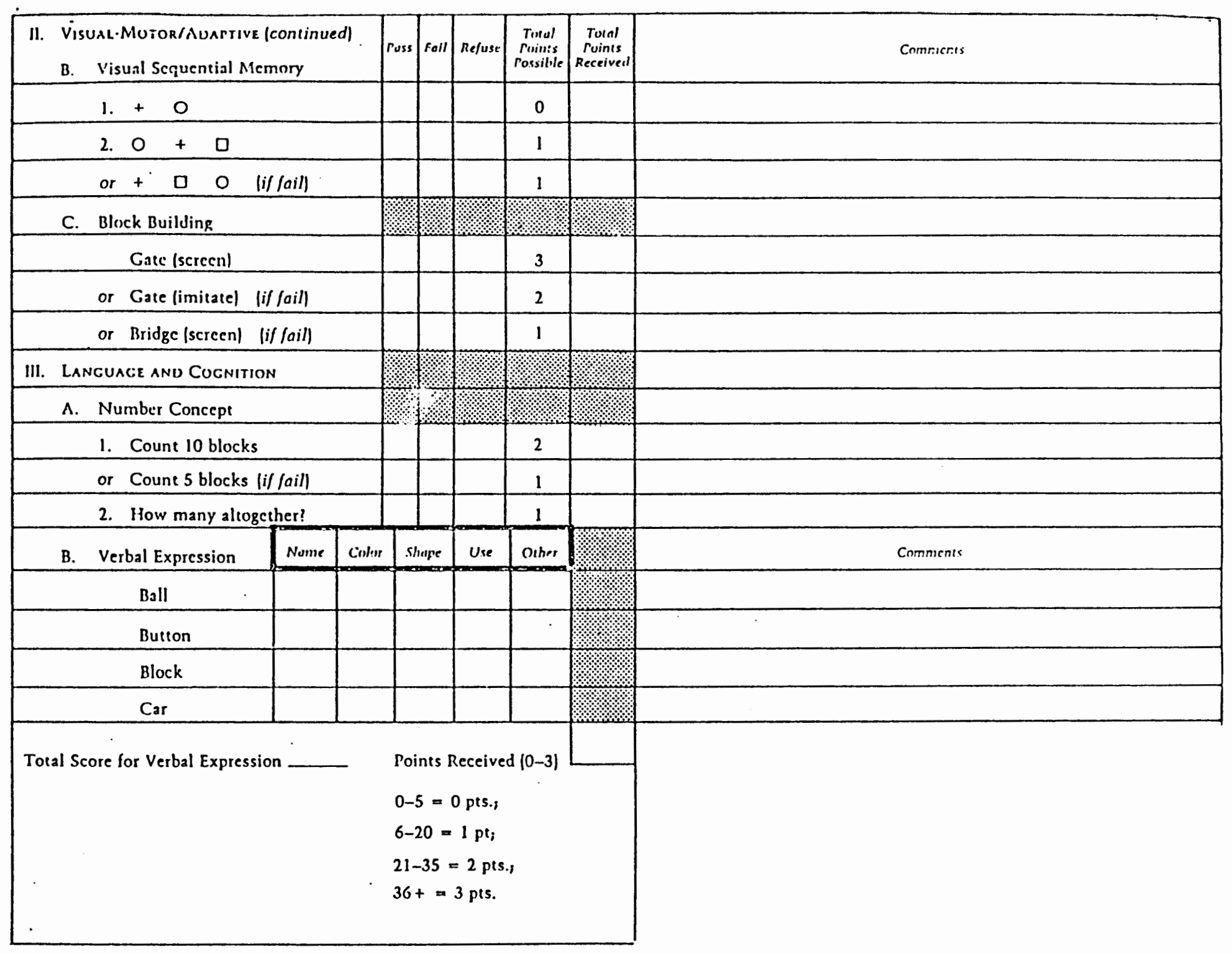




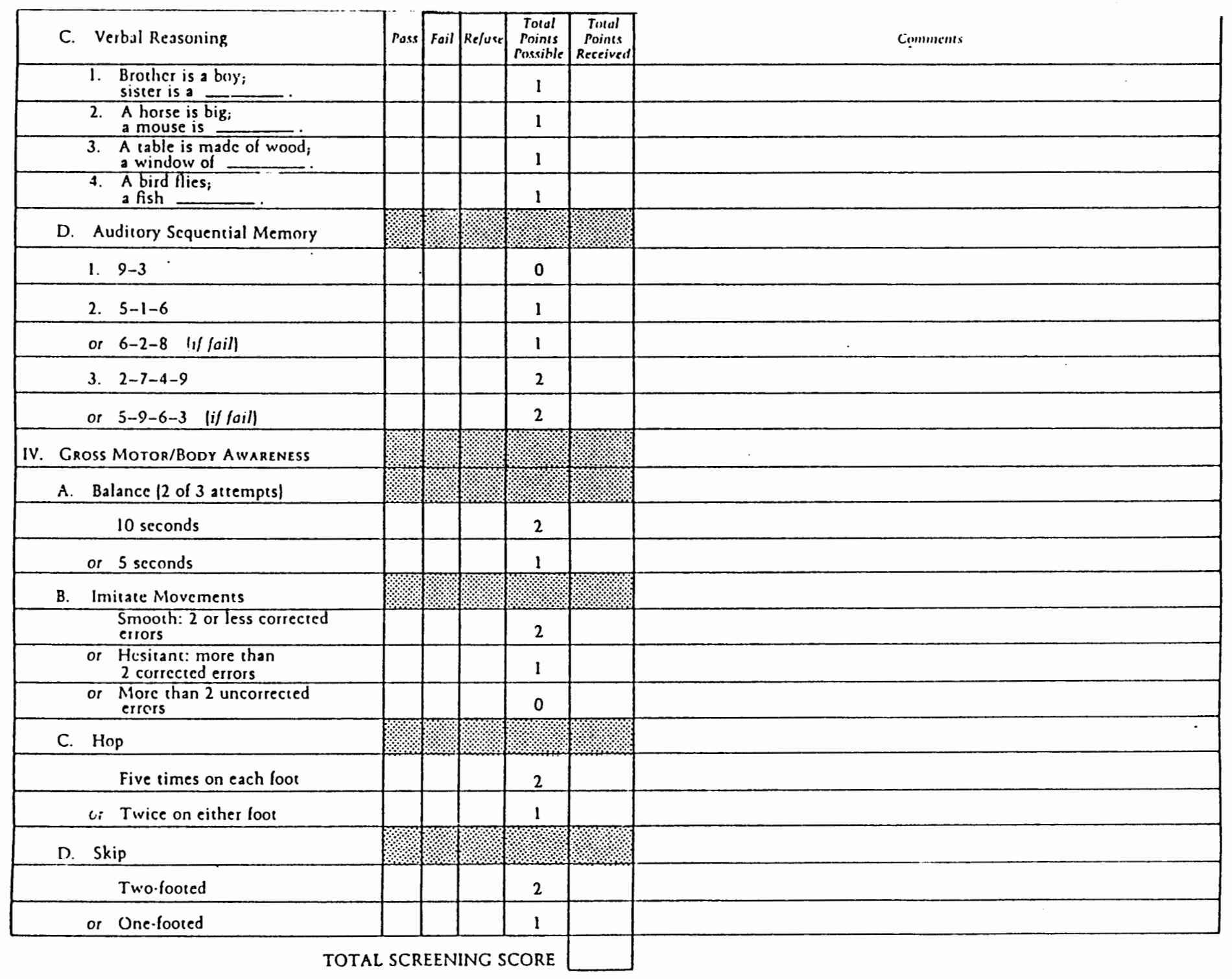


APPENDIX D

RAW SCORES OF TESTS 


\begin{tabular}{|c|c|c|}
\hline Subject & $\underline{D A B}$ & ES I \\
\hline 1 & 107 & 25 \\
\hline 2 & 103 & 28 \\
\hline 3 & 111 & 27 \\
\hline 4 & 118 & 28 \\
\hline 5 & 110 & 26 \\
\hline 6 & 108 & 26 \\
\hline 7 & 106 & 22 \\
\hline 8 & 111 & 26 \\
\hline 9 & 100 & 29 \\
\hline 10 & 96 & 25 \\
\hline 11 & 113 & 29 \\
\hline 12 & 117 & 29 \\
\hline 13 & 109 & 26 \\
\hline 14 & 102 & *17 \\
\hline 15 & * 75 & $* 11$ \\
\hline 16 & 119 & 30 \\
\hline 17 & 118 & 24 \\
\hline 18 & 110 & 29 \\
\hline 19 & 116 & 28 \\
\hline 20 & 101 & 26 \\
\hline 21 & 88 & 23 \\
\hline 22 & 99 & 24 \\
\hline 23 & 114 & 29 \\
\hline 24 & 112 & 28 \\
\hline 25 & 104 & 23 \\
\hline 26 & 119 & 28 \\
\hline 27 & 114 & 27 \\
\hline 28 & 100 & 23 \\
\hline 29 & 111 & 26 \\
\hline 30 & 105 & 21 \\
\hline 31 & 113 & 27 \\
\hline 32 & 117 & 27 \\
\hline
\end{tabular}

* Greater than 1. O standard deviation below the mean 
APPENDIX E

EVALUATION FORM 
Evaluator's Name

Child's Name

Date

Day Care Center/Nursery

Please check the word that applies regarding your opinion of this child's success in their current pre-school setting. Your results will be kept confidential.

Luccessful

Unsuccessful

Somewhat successful 